ARTICLE

https://doi.org/10.1057/s41599-019-0230-0

\title{
The ambiguous influences of fire safety on people with mental health problems in supported housing
}

Jan Georg Friesinger ${ }^{1}$, Alain Topor ${ }^{1,2}$, Tore Dag Bøe ${ }^{1} \&$ Inger Beate Larsen ${ }^{1}$

\begin{abstract}
Over the last few decades, various housing types for people with mental health problems have been developed for use in the community. These housing types differ in their objectives, staff support and design. In this study, we focus on how fire safety influences the lives of tenants in supported housing. The qualitative study was designed with a multi-sited ethnography approach. Fieldwork was conducted in seven different Norwegian supported housing settings in 2017 with 105 participants (29 tenants, 70 staff, five managers, and one planner). The empirical data consist of field notes, recorded interviews and pictures, which were analyzed with grounded theory and situational analysis. The analysis reconstructed how fire safety was organized and tenants' experiences of it. These experiences could be positive (such as feeling protected) or negative (such as feeling annoyed or under surveillance). The tenants coped differently with these situations, and fire safety sets boundaries for tenants. Overall, fire safety was organized differently in the supported housing settings we looked at comparison to in most of the common housing units in Norway. The influences of fire safety on daily life can be understood as ambiguous and can be interpreted as a normalizing factor in a risk society. Thus, we emphasize the need for appropriate and well-considered fire safety as a public health intervention in supported housing.
\end{abstract}

\footnotetext{
${ }^{1}$ Department of Psychosocial Health, University of Agder, Grimstad, Norway. ${ }^{2}$ Department of Social Work, Stockholm University, Stockholm, Sweden Correspondence and requests for materials should be addressed to J.G.F. (email: jan.g.friesinger@uia.no)
} 


\section{Background}

ommunity mental health has been a growing sector since the 1990s, where organizing supported housing for people with mental health problems is the main concern. In this article, we describe how fire safety as a public health intervention is designed in this type of housing and how tenants experience fire safety positively and negatively.

From psychiatric hospitals to supported housing. The mental health sector in Norway and other Western countries has been de-centralized since the 1960s with a move from psychiatric hospitals to new institutions spread throughout the community, resulting in new housing arrangements for people with mental health problems (Ridgway and Zipple, 1990). One goal of this change was to empower patients to become citizens in an inclusive society (Davidson et al., 2010). This implies that people with mental health problems may acquire their own homes to help them develop a sustainable social identity without being marginalized (Borg et al., 2005; Rog, 2004). However, the practices and discourses of psychiatry seem to have been transformed rather than de-institutionalized (Högström, 2018; Parr, 2008; Priebe et al., 2005). New types of interventions and institutions have replaced or supplemented the psychiatric hospital, such as day and activity centers (Larsen and Topor, 2017), and different forms of support in one's own home or in residential settings, such as supported housing (Nelson, 2010). The settings of supported housing, then, can be either 'congregate' with on-site support from staff as in residential facilities or 'independent' with off-site support from professionals as in apartments (McPherson et al., 2018; Tabol et al., 2010). In the present case, we looked primarily at supported housing in congregate settings. Within these settings, fire safety is an important issue for tenants.

Building and tenancy regulations. Supported housing differs from standard housing for legal reasons. The first concerns technical requirements for buildings. In Norway, the type and frequency of fire protection devices (e.g., smoke detectors, sprinklers, and fire alarm systems) are regulated in buildings (DIBK, 2010, 2017). Buildings are ranked in hazard classes according to the following aspects: The more complex and larger the buildings, the more the use of fire protection is required and automatized; similarly, the higher the number of people the buildings are meant to house and the lower the escape capability they have, the more fire protection is automatized (DIBK, 2017, pp. 27-33). Thus, hotels and care homes are ranked in the highest hazard classes and must have a fire alarm system and sprinklers, while common housing units require only smoke detectors. Most of the housing settings in this study are defined in architectural and technical plans as care homes.

The second reason is that the housing is described in tenancy contracts as service or adapted housing for people with special dwelling needs according to the Norwegian Tenancy Act (KMD, 2009). Tenancy agreements are limited for this group and even more by the specific house rules written by the staff for that particular place (Andersen et al., 2016). Tenants living in these specialized buildings may be understood as unable to manage daily life in the same way as people in general. This point is relevant when looking at fire safety and is why this topic seems to be a bigger issue regarding supported housing than in other types of accommodation with similar fire safety installations. Therefore, a closer look at domestic fire risk and public health interventions in general is needed.

Domestic fire risk and public health. Some vulnerable groups, such as children, older people, people with reduced mobility and people with mental health problems or learning disabilities or substance abuse, have higher risk of experiencing a house fire (Halvorsen et al., 2017). An Australian study concluded that the risk of a fatal accidental residential fire is higher for smokers, especially if they fall asleep and use alcohol and/or other substances compared with non-smokers (Xiong et al., 2017). Concerning fire risk management in mental health services, one study recommended increased awareness for psychiatric patients (Phelan and Fisher, 1993), while another recommended early intervention to prevent fire settings among young people (Dolan et al., 2011). Other studies focused on technical solutions for reducing the risk of fires (Doughty and Orton, 2014; Schulz et al., 2008). In sum, the studies emphasized that people with mental health problems are at a greater risk of experiencing a domestic fire and discussed different strategies for reducing the risk of fires. However, the literature does not address fire risk in supported housing as a separate research subject. Researchers focus on groups who are more likely to start a fire.

Reducing the risk of domestic fire incidents is a substantial task in public health interventions. Therefore, the questions of how fire safety as an intervention is better understood and how it is experienced in daily life should be addressed in a wider social context as the authors of a review recommended (Clark et al., 2015). Accordingly, a framework with multiple levels ranging from the individual to societal provide as a more complete understanding of fire risk than traditional fire risk research. Clark and Smith (2018, p. 759) demonstrated this "wider understanding of contextually situated risk knowledge and practices" in a recent study on daily experiences of owning, maintaining and testing smoke detectors in the United Kingdom (UK). We agree with their approach and with this study aim to contribute to improving the understanding of fire safety experienced by people with mental health problems and how it is organized in supported housing.

Therefore, we addressed the following research questions: What are the elements of fire safety, and how are they organized in supported housing for people with mental health problems? How do the fire safety elements influence the tenants' daily lives? In the following, we introduce the study method, present our findings and discuss the ambiguity of fire safety.

\section{Methods}

Data collection: multi-sited ethnography. To address the research questions, we selected ethnographical fieldwork to gather rich descriptions (Charmaz, 2014) — as far as possible—of tenants' daily lives (Hammersley and Atkinson, 2007). In comparison with traditional ethnographies, which intend to obtain a comprehensive representation of a cultural phenomenon by collecting data over years, we favored multi-sited ethnography (Marcus, 1995). We chose participant observations in the field (Lüders, 2004), took photographs of the buildings, rooms, interior and objects (Harper, 2004) and conducted unstructured interviews with tenants, staff and managers during fieldwork in which we asked them to describe the daily practices in the dwellings (Spradley, 1979). Despite the benefits of multiple sites, this type of ethnography loses descriptive details compared to traditional single-site ethnography because the field visits are shorter (Nadai and Maeder, 2005). Consequently, we took the position of interpretive ethnography (Charmaz and Mitchell, 2001; Denzin, 1997; Prus, 1996) by simultaneously collecting data and analyzing them.

The project was approved by the Norwegian Center for Research Data (number 50067) in autumn 2016. Then, over a sixmonth period, the first author recruited 105 participants (29 tenants, 70 staff, five managers and one planner) and beginning in 


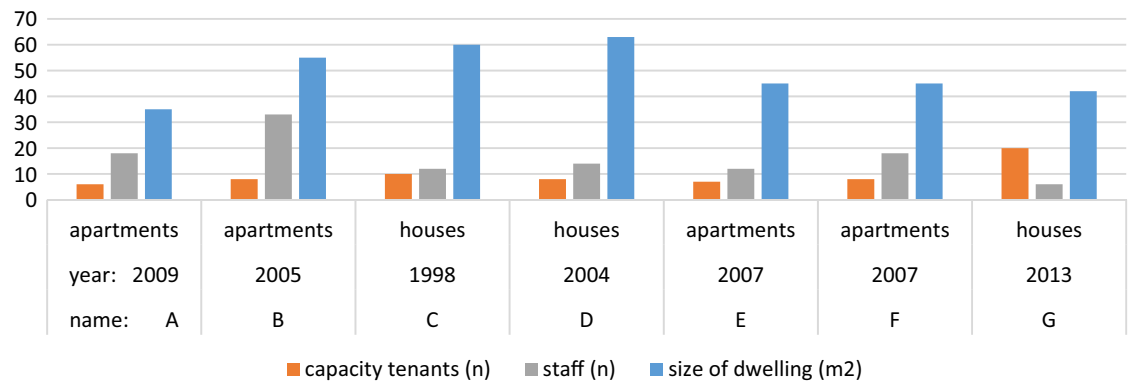

Fig. 1 Characteristics of the housing sample

January 2017 visited seven supported housing sites in southern Norway at different hours. During the fieldwork, there were twice as many staff as tenants present, a ratio that corresponds to the housing characteristics (Fig. 1).

The duration of each field visit varied from four to eight hours over a period of between one and two weeks at each dwelling. The first author participated at mealtimes, played games and watched television with the tenants and helped them with their computers. The observations were documented in 212 pages of field notes during the visits, six recorded interviews and almost 900 pictures. The data from this study on fire safety are based on these overall empirical data. Access to the housing was approved by the head of the community mental health service and by each manager of the housing site in question. All participants signed informed consent forms, which presented the study and its aims, and anonymity was guaranteed to all participants. The recruitment process started with a presentation for the staff, and later for the tenants in the common area or activity center of each housing site. Some tenants did not participate, but they accepted the researcher's presence. In sum, we based this study on the ethical issues identified by Murphy and Dingwall (2001) to avoid harming participants and to offer a beneficial understanding of their daily lives.

Data analysis. The collected data were analyzed with the help of Clarke's (2005) situational analysis and Charmaz's (2014) constructivist version of grounded theory. Both are developments of Strauss and Glaser's grounded theory and have roots in pragmatism and symbolic interactionism. In addition, a central premise of both analyses is that researchers and the researched coconstruct the empirical data meaning they are socially involved in the research process. Grounded theory focuses on the analysis of social processes; situational analysis focuses on relationality. The analyses can be used together and are recommended with multisited ethnography (Clarke et al., 2018 p., 366). Moreover, critical reviewers have appraised situational analysis's multi-site concept as positive but thought that its uncertainty might be a challenge (Mathar, 2008). Clarke herself $(2015$, p. 141) saw grounded theory and situational analysis as being analytically strong but weak in re-representation. To conclude, for the purpose of this study, multi-sited ethnography and postmodern assumptions are appropriate because of the need for "thick analysis" (Fosket, 2015, p. 196).

In this study, we first analyzed the field notes, transcripts of the interviews and photographs with the logic of initial coding (Charmaz, 2014; Glaser, 1978; Glaser and Strauss, 1967). During the fieldwork and later, the authors met several times and discussed preliminary codes, interpretations of the data and analytical issues. From the beginning of the data collection, fire safety was an important theme for the participants, and we coded it frequently. Theoretical sampling was challenging because the time for fieldwork per housing site was limited. Increasingly, the codes crystallized into saturated categories in focussed coding rounds by re-coding, constant comparison and memo writing. In addition, qualitative data analysis software (ATLAS.ti) in which we imported all the data, including the photographs, supported these steps analytically. We coded the data with the software, and visualized and sorted our categories. We created the categories a) organization of fire safety, b) positive experiences of fire safety: protection and possibilities, c) negative experiences of fire safety: annoyance and irritation, d) how to cope with annoying fire safety objects and e) boundaries created by fire safety: restrictions and marginalization.

In addition, the analytical work was carried out by re-making situational maps (Clarke, 2005; Clarke et al., 2018). In particular, we drew a map of the tenants' housing situation, focussing on fire safety by filling in the major elements (human, nonhuman, material, discursive, and symbolic) in a messy way. Then, we ordered these elements according to the situational matrix and analyzed their interrelationship. Finally, we created a relational map that revealed the all-embracing network of fire safety elements in the supported housing settings, which we present later.

Limitations. According to qualitative research criteria, the findings of this study are limited to the housing sample (Lincoln and Guba, 1985; Steinke, 2004), but could be transferable to similar Norwegian settings for people with mental health problems living in supported housing. Although the European Commission planned in 2017 to regulate fire safety in buildings for member states, there is no consensus about international standards for fire safety in buildings yet. In addition to these legislative differences, cultural and societal differences across Europe are important limitations. Therefore, the present findings are not applicable to other countries but could be compared to findings for other countries. In addition, the insights of this study on fire safety as a public health intervention could be transferred to other people at high risk of experiencing a domestic fire or other public health interventions, such as healthcare technologies in the care for older people.

Other limiting considerations are linked to the research role we took in the fieldwork, our previous understanding as former workers in mental health services and the translation of the participants' quotations from Norwegian to English. We emphasized the need to reflect critically about these issues in our research journal, discussions and memo writings.

\section{Results}

Housing characteristics. In Fig. 1, we present the characteristics of the participants' supported housing settings (named from A to G). First, all housing sites had been built within the last 20 years (1998-2013) for the purpose of offering a home to people with mental health problems (with and without substance abuse). The housing settings were all operated by municipal landlords and 


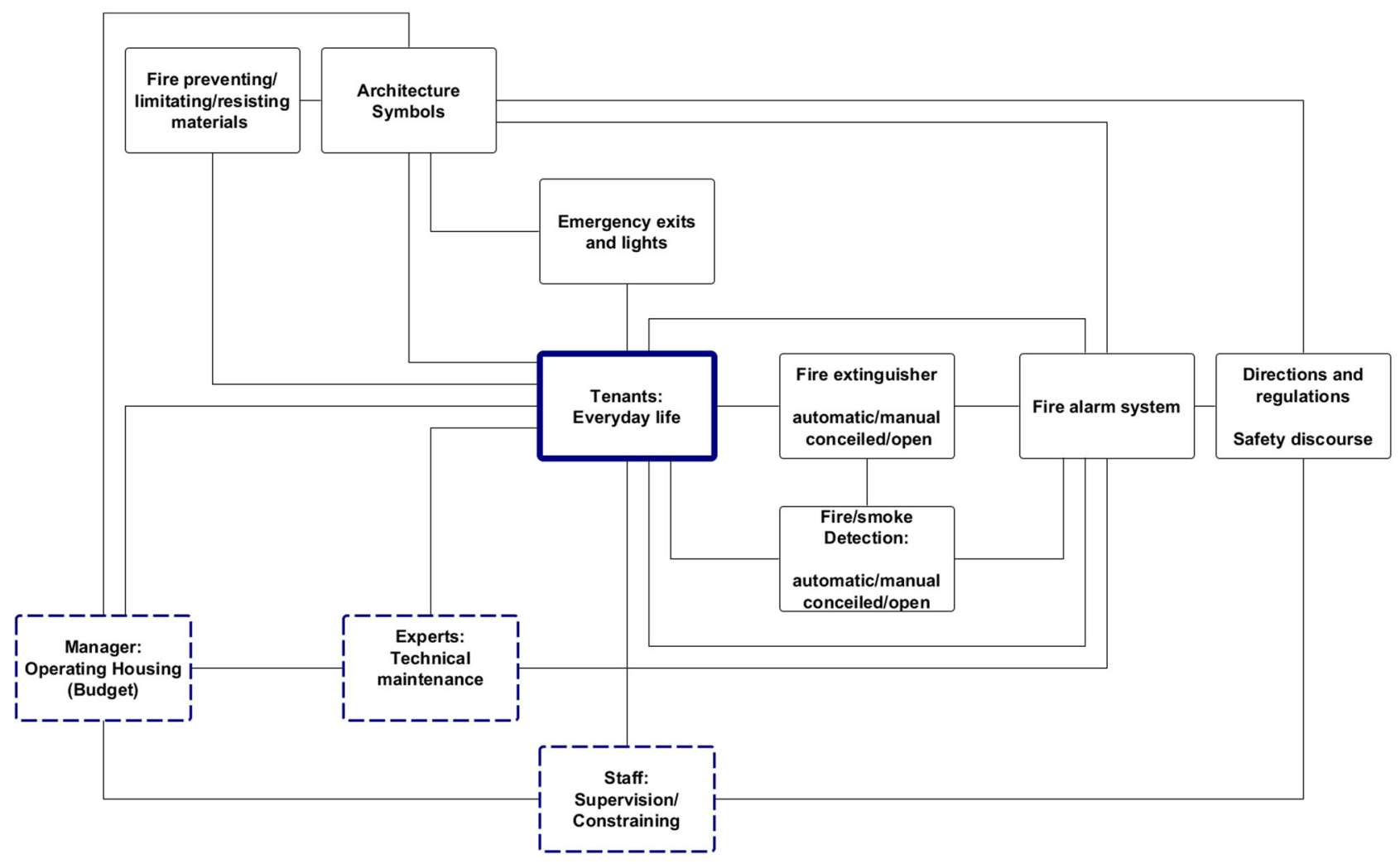

Fig. 2 Map of fire safety in supported housing

had staff support. There were two types of housing: a facility with congregate apartments, a main entrance, staff and common rooms and co-located small houses with a staff base and an activity center adjacent. The living spaces were generally smaller in the apartments $\left(35-55 \mathrm{~m}^{2}\right)$ than in the houses $\left(42-63 \mathrm{~m}^{2}\right)$. The youngest tenant was 22 years old, and the oldest was 62 . All housing settings were located in southern Norway and had different types of fire alarm systems.

The map of fire safety in supported housing. In the tenancy contracts, the tenants were described as having special housing needs, and their housing settings were labeled as care homes. Many of the tenants were smokers, and some had used alcohol or drugs, which increased the risk of experiencing a domestic fire. The tenants were not seen as fully capable of living by themselves in terms of being responsible. This perspective was applicable to fire safety as well. The situational analysis revealed a network of fire safety elements (Fig. 2), which had ambiguous influences on the tenants and their practices. In the following sections, we present the organization of fire safety, and then the different types of influences on daily life in the buildings, such as the tenants' positive and negative experiences.

Organization of fire safety. All the supported housing sites we visited had fire alarm systems (Fig. 2) installed in accordance with Norwegian legal technical requirements (DIBK, 2010, 2017). However, this had not always been the case. For example, newer buildings met this standard, while the older dwellings $C$ and D did not. C and D were not automatized until two years before after the manager pointed out this deficiency to the landlord. In this process, fire protection elements, such as smoke detectors and manual fire alarm call points, were electronically linked together in a fire alarm control panel, usually placed in the main entrance of the housing. Beside this panel, an evacuation and orientation map of the building was posted, which indicated the location of the connected elements. If a sprinkler is triggered in a room, the water pressure falls, and a sensor signals this to the panel, which activates the alarm.

Turning to the technical work of planning housing, architects had to integrate fire and smoke barriers, appropriate emergency exits and lights, and fire resistance and limiting materials according to the technical requirements for construction works in Norway (DIBK, 2010, 2017). The planners thus not only met the requirements for fire safety but also affected aesthetical perceptions with their choice of materials and design. One of the planners for housing G stated, "The small houses are designed to fulfill the common housing standard and are constructed as fire barriers each to prevent a fire from spreading." Furthermore, they used bricks to achieve better building quality instead of concrete. Similarly, the manager of housing B saw "fire safety as a leading concept for re-designing the housing after a domestic fire. Even though you have the freedom to plan rooms." This last expression was in accordance with the tenants and staff of the housing, who criticized the reconstruction of the rooms because it degraded the housing standards. They experienced fire safety as an excuse by the planners to accomplish their latest version of house design.

The managers of the supported housing sites tried not to exceed their budgets, although some had to cover the extra costs of repairing technical installations that were broken by tenants, such as fuse boxes, water meters, and fire safety elements. As a result, the housing $G$ planners transferred these objects to a maintenance room inaccessible to tenants. Instead of the visible smoke detector in the units, there was a small almost invisible hole on the ceiling. Through this hole, air from the living area was extracted to the smoke detector in the maintenance room. Two of these houses had reinforced fire safety with a heat detector and a differently designed smoke detector in the living area. Concealed sprinklers were installed in the ceilings of housing $G$, which would pop out when activated. A similar sprinkler design was 
installed in housing $\mathrm{E}$ and $\mathrm{F}$ in contrast to the remaining housing, which had a visible design. Another example of interior materials is the device used to prevent fires when a meal is prepared on the stove. This device could be installed above the stove (the new version) or in the fuse box (the older version).

These systematizations of fire safety resulted in legally required maintenance of the fire alarm systems by experts such as authorized electricians. Thus, the level of dependency on experts was generally increased. During the fieldwork, several fire alarm systems were checked by electricians during the annual inspection. Thus, the staff or the managers had to announce the check by means of an information letter to the tenants because the electricians needed to be let into the apartments. The check was conducted whether the tenants were present or not, and the electricians were often followed by staff. Another interesting finding concerning the systematization was that most of the staff was unaware of the fire safety solutions in the housing. Although each site had one person responsible for operating the fire protection system, most of the staff and tenants had no idea how it functioned. As an example, in housing G only the architects and planners knew the details of the hole extraction smoke detectors in the ceiling. Despite the fire alarm system, several employees supervised tenants to prevent fires. Accordingly, in housing $C$ staff helped a tenant unplug electronic devices that were a fire hazard, and in housing E, staff removed a broken electrical stove. Generally, the tenants had to take care of fire safety by themselves. They had to follow advice provided on the information board-how to act in the case of a fire-and practice in an annual fire drill.

Positive experiences of fire safety: protection and possibilities. In the previous section, we showed that the organization of fire safety in the supported housing sample had a common pattern but differed according to the design and configuration of individual elements such as the smoke detector or sprinkler. In many cases, the tenants, of course, appreciated the fire safety systems. After the systematization process, these tenants felt safer because of the fire alarm system. A tenant said, "We feel happy with the new fire safety." Tenants who had experienced a domestic fire in particular appreciated the system. Without this system, a recent domestic fire in one dwelling could have resulted in serious damage.

The tenants did not talk about bad experiences with some of the fire safety elements such as the newer version of the fire prevention device for the stove, the open sprinkler version and the hole in the ceiling solution with the smoke detector. Moreover, the tenants had their own creative ways of using elements of fire safety. The emergency and fire exit doors on the ground floor were used to bring in unapproved visitors. These visitors could easily bring in alcohol and drugs without being seen by staff. This redefinition practice was used to avoid being controlled.

Negative experiences of fire safety: annoyance and irritation. At the same time, tenants had difficulties with the fire alarm system and stated that they were annoyed by frequent false alarms. There were several reasons for these false alarms, such as smoking, high sensitivity, and inappropriately located smoke detectors, which could be activated by showering or cooking. Other reasons were simply testing the functionality of the detector by smoking near it or abuse of the fire alarm call point. A tenant said, "I never had such a call point before in my living room. It feels strange. When they installed it there, I wanted to push the button. I never had such a feeling before" (see Fig. 3).

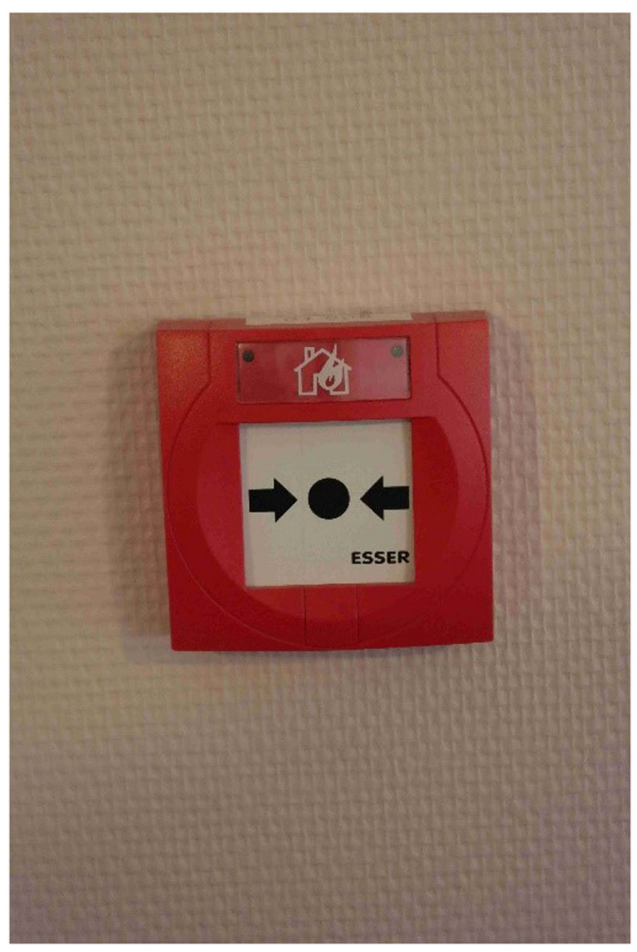

Fig. 3 Fire alarm call point in the living room of an apartment

In addition, the staff said that a few tenants pulled out the concealed sprinklers to see what was behind them. Other tenants stated that they were suspicious of the visual alarm unit in their apartment. Several tenants reported that they felt monitored by the smoke detectors, which blinked periodically to signal proper function. A tenant said, "I feel that I'm monitored. Various colors are flashing from the smoke detector in my apartment." Another tenant also disliked the electronic installations and felt under surveillance, in particular by the emergency light that indicated the emergency exits in the event of a fire. Staff reported that they observed that some tenants "became paranoid due to the blinking smoke detector or emergency light." A manager generalized that "when they are under the influence of drugs, they get paranoid about these objects. They feel they are under surveillance by us and destroy them."

How to cope with annoying fire safety objects. How did tenants react to these annoying situations caused by the smoke detector? As mentioned, several tenants damaged the detectors. In the case of a former tenant, the staff had to protect the detector with a metal cage. Another tenant removed the internal parts of the detector and put the empty case back in the ceiling. A staff member tried to explain to the tenant several times how fire safety and the detector worked, which helped for a while and prevented the tenant from damaging the detector. In general, most of the tenants had no comment, and they just coped with the annoying situations by ignoring the false alarms or blinking smoke detectors. However, several tenants used a different strategy: They covered the disturbing objects. Thus, one tenant who also removed bulbs in the ceilings placed masking tape over the LED lamp of the smoke detector to conceal the blinking light (see Fig. 4).

A staff member mentioned that some tenants put plastic bags or plastic gloves over a sensitive and annoying smoke detector to disable it. For example, one did this in the kitchen when cooking to avoid activating the fire alarm. Some participants said that only the concealed sprinkler version was a concern, and it was pulled 


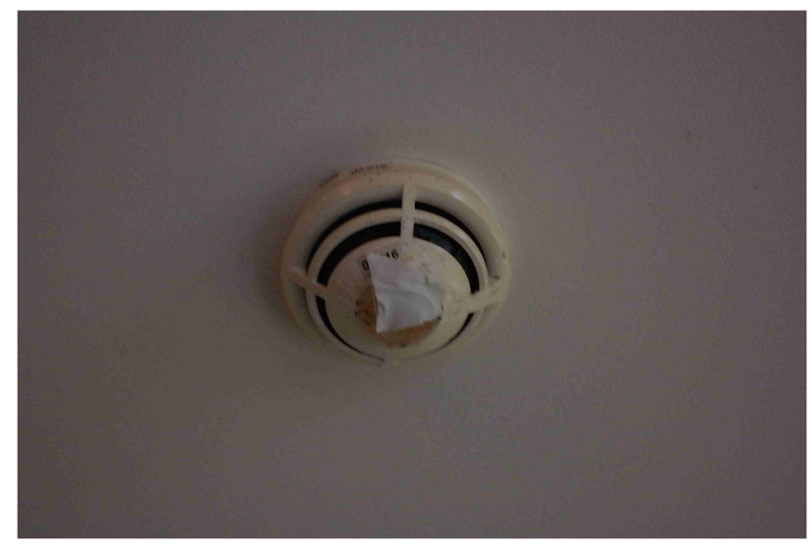

Fig. 4 Masking tape on smoke detector

out by a few tenants. However, the sprinkler was not generally a cause of concern.

Boundaries created by fire safety: restrictions and marginalization. The staff were concerned about fires, and they tried in different ways to protect tenants. At the same time, this protection affected tenants' privacy. First, their privacy was invaded, and the fire safety rules restricted tenants' daily lives. Even if the tenants' privacy was respected in general, the staff could unlock doors because of fire safety issues to check who was actually in the building. This was usually practiced only in the case of fire drills or fires. One manager also used the risk of fire to support their argument for checking on tenants during the night. They needed to know who was in the building because of fire safety requirements. Alternatively, the tenants could also protect their private dwelling units by denying access to others, as one tenant did with the fire fighters who came to maintain the fire extinguishers. In several renovated housing units, smoking was prohibited, and tenants had to smoke outside, even after a modern fire alarm system was installed. Furthermore, one tenant was not allowed to have a lighter because of he or she started a fire previously. Instead, the tenant had to come to the staff room to light cigarettes. Another issue was that tenants were prohibited from using fan ovens because of fire safety issues.

One tenant felt disempowered by the fire prevention device for the stove and said, "My apartment looks like a psychiatric hospital because of safety issues. But why is there a device installed in the fuse box to prevent a fire while cooking?" The device allows cooking on the stove for only 30 minutes, and then the tenant has to activate it again. The tenant also stated that this was paradoxical because they were not being trusted to use the stove in the proper way, and the fire prevention device was accessible in the fuse box, and thus, was also a dangerous object. In contrast, tenants had no comments about the fire prevention device installed above the stove, which automatically checked the temperature with sensors. Moreover, tenants in another supported housing building referred to fellow tenants who lived in houses with reinforced fire safety as "arsonists." This statement could be interpreted as a kind of stigmatization and was also applicable to the system of public housing as one manager reported:

The municipal landlord demands that sober tenants with previous problematic tenancies can only live in apartments with a fire alarm system including sprinklers. There are only some newer buildings which fulfill these demands, and that is the reason why the transfer process is so slow, and they are held back in their current housing [with drug abuse problems].

In other words, people who had several problems in previous housing that included starting domestic fires were marginalized in the public housing system.

\section{Discussion}

Ambiguous influences of fire safety: some reflections. None of the literature on domestic fire risk discussed in the introduction mentioned that fire safety could be seen as a double-sided phenomenon, which affects tenants' daily lives in various ways. In comparison to this one-sided view, this study identified that the influences of fire safety can be described as ambiguous (Fig. 5).

The ambiguous influences of fire safety on tenants' daily lives were characterized by positive experiences concerning protection and by experiences of discrimination and disturbance, which the tenants handled differently. In addition, the fire safety in the supported housing sample differed from that in standard Norwegian housing units, and the tenants did not have the same opportunities to move in the closed system of public housing. Some tenants had been involved in domestic fires, and were at a higher risk of experiencing a domestic fire again. Thus, high standards for fire safety were considered reasonable by managers, planners, and other tenants and were necessary to fulfill legal requirements. Nonetheless, the planners had to configure fire safety as a public health intervention as the findings show. For example, the planners had different alternatives for concealing fire safety elements, which reduced annoyance and still fulfilled the requirements for proper fire safety. In comparison, Clark and Smith (2018) pointed out in their study on smoke alarms in the UK that annoyance at repeated false alarms was a common experience for participants who had been recruited from the general population. Some participants said that they disabled the alarms by removing the battery, but in most of the cases, "once installed, smoke alarms remained out of sight" (p. 760).

The understanding of fire risk in supported housing is framed by multiple levels (Clark et al., 2015), which might be one reason for the ambiguity of the influences of fire safety. For example, tenants who are smokers or alcohol or drug users individually have higher fire risks and live near each other in congregate housing settings. Even fellow tenants stigmatize tenants associated with previous domestic fires as "arsonists." Those tenants have difficulty finding other housing.

If fire safety focuses only on reducing fire risk in supported housing without seeing the bigger picture, we will miss the importance of how these small material objects might have a significant influence on tenants' daily lives. We also might ignore that these types of fire safety systems might create discrimination by overemphasizing the risk of fire. Therefore, reinforced fire safety might harm tenants or be dysfunctional. For example, one of the supported housing sites we visited was partly damaged by a fire one year after the fieldwork despite the highest fire safety standards and strict rules prohibiting smoking inside. We continue this critical discussion in regard to two key aspectsrisk in postmodern society and normalizing biopower.

Risk in postmodern societies. Overall, fire safety elements are designed to reduce the risk and harm of fires, but these elements seem to influence tenants in other ways than intended, which could be interpreted as side effects. These unintended consequences conform to the theory of reflexive modernization (Beck et al., 2003) and share the descriptions of postmodern societies that risks are socially constructed (Lupton, 1999). Reflexive modernization refers to the "second-order rationalization" (Beck et al., 2003) of modern industrial societies resulting in risk 


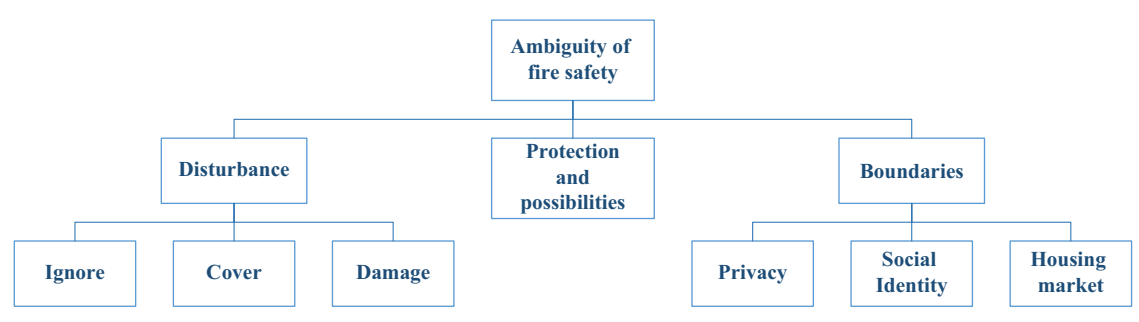

Fig. 5 Ambiguity of fire safety in supported housing

societies, which reduce and produce risks. In risk societies, individualization and globalization multiply not only choices but also boundaries (Beck, 1992), causing unexpected and unintended consequences, such as some tenants feeling watched by the blinking smoke detector. In postmodern societies, knowledge increases expansively, which must be handled by expert systems, and results in an increased dependency on them (Giddens, 1991). Thus, experts such as engineers who develop, install, and maintain fire alarm systems are required. To sum up, as Zygmunt Bauman (1995, p. 279) stated, "The risks are our own products."

Similarly, actor network theory (ANT) offers an explanation frame for the fire safety elements, which explores their complexities rather than simplifying them (Mol and Law, 2002). ANT also shares assumptions about materiality with Foucault, but is more concerned with "possible modes of ordering" in modernity than with "limits of the conditions of possibilities" (Law, 2002). Latour (2003) criticized Beck for his modernization concept because it is narrowed to describe the shift between first and second modernity. In ANT, modernization is only a question of interpretation, because "we have never been modern" (Latour, 1993). Thus, fire safety in the supported housing sample can be compared with Latour's illustrations of seat belts (1992) and speed bumps (1994), in which driving slowly or fastening your seatbelt is inscripted in materiality. In other words, avoiding fires is transferred to nonhuman elements such as the fire prevention device for stove use or other humans such as the staff. This shifting process causes a moral displacement by rational issues of modernization. As a result, taking care of yourself is abandoned. This aspect can be seen with the tenant who felt disempowered because of the fire prevention device in the fuse box and the employees who were unaware of the fire alarm solutions. However, from an external perspective, it does not matter as long as the risk of fire is reduced. To summarize, we wanted to highlight the ambiguous findings with the angle of ANT and Beck, "because it shifts attention from the mainstream" (Latour, 2003, p. 46). Next, we discuss the findings further with Foucault's biopower concept, understood as a kind of double risk related to fire risk itself and to the fact of having mental health problems.

Normalization and biopower. Above all, the organization and practice of fire safety in supported housing can be interpreted as a normalizing process for tenants. With normalization, we do not mean the adjustments for equal rights for marginalized groups. Instead, we connote normalization as Foucault did, as a sort of "distributive management" (1984) of individuals related to a norm, which is the outcome and producer of this systematic distribution. This system is effected by "biopower" that transforms the human body, and "bio-politics" (1984) that regulates the population. For Foucault (2006), this normalizing regime of surveillant power and knowledge affects all domains, from law to science, and leads to self-regulation. Rabinow and Rose (2006) identified key aspects of the transformative knowledge of biopower today. These concern vital processes of humans being treated as objects and working on themselves by subjectification.
Transferring this idea to the aspects of fire safety, one might understand its ambiguous system of protection as influences on the living human body, its objectification as calculation of the risk of starting a fire, and fire safety practices as self-fulfilling purposes. These aspects become part of tenants' lives through internalization processes, which are barely reflected.

Tenants become clients and regulate themselves within a "culture of life" (Knorr Cetina, 2005). Similarly, fire safety in their dwellings can be understood as disciplinary technology, which normalizes and optimizes the tenants within a rationally organized scheme of fire reduction. A stricter regulatory system than the ordinary tells them that they are more likely to cause a fire. Such a system might create an identity as sicker and more abnormal than they necessarily are. This also conforms to the process of victim blaming for groups who appear to be more at risk of fire, which Clark and colleagues (2015) outlined in their review. To refer to the present findings, having a fire alarm call point in the living room of a supported housing unit can then remind you of this sort of double risk.

In this study, we have seen that small changes in the organizational or technical implementation of fire safety can turn a negative experience into a positive one. The following points from the findings have valuable implications for practice: First, fire safety in supported housing should be organized to guarantee appropriate fire protection and to avoid unnecessary annoyance. Thus, planners and landlords might prefer the installation of smoke detectors without blinking LED lights in supported housing, and they should be careful about the location of the smoke detector in the ceiling to avoid false alarms. Second, planners and landlords should be aware of the choice of fire safety devices to avoid the increase in limitations caused by the fire safety system. People with mental health problems already face many limitations in their daily lives because of their personal problems and because of the way they are treated by others (Moon, 2000). Thus, tenants should be offered a safe good-quality home that is not decreased by the design of fire safety devices or by fire-resistant materials, which make tenants feel abnormal or marginalized. The automatic device installed above the stove to prevent a fire is a good design example, while the device installed in the fuse box is not. Third, health care professionals engaged with supported housing should be aware that fire risk and protection might result in discrimination and marginalization of tenants. The professionals should balance house rules and tenants' own responsibility for preventing domestic fires, which is framed by the installed fire alarm system. Finally, tenants' experiences should be heard in planning and organizing supported housing, including fire safety.

\section{Conclusions}

To conclude, fire safety is organized differently in supported housing for people with mental health problems than in most standard housing units in Norway. Furthermore, the influences on tenants' daily lives can be protective and annoying, or limiting. This ambiguity of fire safety in housing can be interpreted as 
having unintended and unexpected consequences in a risk society and as biopower strategies for regulating living human beings. Nonetheless, we do not want to minimize the importance, for saving human lives, of fire safety as a public health intervention in housing in general. In particular, we emphasize the need for appropriate fire safety in public housing. Fire safety should be taken seriously by landlords and should not be affected by economic factors. However, this study showed that tenants may have negative experiences of reinforced fire safety and inappropriate installations, such as the fire alarm call point in the living room, that make them feel abnormal. Fire safety installations as public health interventions should also be well considered and match user involvement. Thus, normalization should involve tenants in creating a home, as all citizens do, including how fire safety should be managed.

\section{Data availability}

All data generated or analyzed during this study are included in this published article.

Received: 30 July 2018 Accepted: 28 January 2019

Published online: 19 February 2019

\section{References}

Andersen AJW, Larsen IB, Topor A (2016) Caring through discipline? Analyzing house rules in community mental health services in Norway. Scand Psychol 3. https://doi.org/10.15714/scandpsychol.3.e1

Bauman Z (1995) Life in fragments: essays in postmodern morality. Blackwell, Oxford; Cambridge

Beck U (1992) Risk society: towards a new modernity. Theory, culture and society. Sage, London

Beck U, Bonss W, Lau C (2003) The theory of reflexive modernization problematic, hypotheses and research programme. Theory Cult Soc 20(2):1-33. https://doi. org/10.1177/0263276403020002001

Borg M, Sells D, Topor A et al. (2005) What makes a house a home: the role of material resources in recovery from severe mental illness. Am J Psychiatr Rehabil 8(3):243-256. https://doi.org/10.1080/15487760500339394

Charmaz K (2014) Constructing grounded theory. 2nd edn. Introducing qualitative methods. Sage, London; Thousand Oaks, Calif

Charmaz K, Mitchell RG (2001) Grounded theory in ethnography. In: Handbook of ethnography. SAGE Publications Ltd, Thousand Oaks. pp. 160-174

Clark A, Smith J (2018) Owning and testing smoke alarms: findings from a qualitative study. J Risk Res 21(6):748-762. https://doi.org/10.1080/13669877.2016.1240707

Clark A, Smith J, Conroy C (2015) Domestic fire risk: a narrative review of social science literature and implications for further research. J Risk Res 18 (9):1113-1129. https://doi.org/10.1080/13669877.2014.913660

Clarke AE (2005) Situational analysis: grounded theory after the postmodern turn. Sage Publications, Thousand Oaks

Clarke AE (2015) Feminism, grounded theory and situtional analysis revisted. In: Clarke AE, Friese C, Washburn R (eds) Situational analysis in practice: mapping research with grounded theory. Left Coast Press, Walnut Creek, California, $\mathrm{p}$ 119-154

Clarke AE, Friese C, Washburn R (2018) Situational analysis: grounded theory after the interpretive turn, Second edition. SAGE, Los Angeles

Davidson L, Rakfeldt J, Strauss IS (2010) The roots of the recovery movement in psychiatry: lessons learned. Wiley-Blackwell, Chicester; Hoboken

Denzin NK (1997) Interpretive ethnography: ethnographic practices for the 21st Century. Sage Publications, Thousand Oaks

DIBK (2010) Regulations on technical requirements for building works (TEK10). Den sentrale myndigheten for det bygningstekniske regelverket, Oslo. https://dibk. no/byggereglene/Building-Regulations-in-English/. Accessed $31 \mathrm{Mar} 2017$

DIBK (2017) Regulations on technical requirements for building works (TEK17). Den sentrale myndigheten for det bygningstekniske regelverket, Oslo. https://dibk. no/byggereglene/Building-Regulations-in-English/. Accessed 31 Mar 2017

Dolan M, McEwan TE, Doley R et al. (2011) Risk factors and risk assessment in juvenile fire-setting. Psychiatry Psychol Law 18(3):378-394. https://doi.org/ $10.1080 / 13218719.2011 .559154$

Doughty K, Orton M (2014) AT and telecare to manage fire risks in the homes of older and vulnerable people. J Assist Technol Hove 8(1):35-43. https://doi. org/10.1108/JAT-08-2013-0021

Fosket JR (2015) Situating knowlegde. In: Clarke AE, Friese C, Washburn R (eds) Situational analysis in practice: mapping research with grounded theory. Left Coast Press, Walnut Creek, California, p 195-215
Foucault M (1984) Bio-power. In: Rabinow P (ed) The foucault reader. Pantheon Books, New York, p 257-289

Foucault M (2006) Psychiatric power: lectures at the College de France, 1973-74. Palgrave Macmillan, Michel Foucault, Lectures at the Collège de France, Hampshire

Giddens A (1991) The consequences of modernity. Polity Press, Cambridge

Glaser BG (1978) Theoretical sensitivity: advances in the methodology of grounded theory. Sociology Press, Mill Valley, Calif

Glaser BG, Strauss AL (1967) The discovery of grounded theory: strategies for qualitative research. Aldine, New Brunswick

Halvorsen K, Almklov PG, Gjøsund G (2017) Fire safety for vulnerable groups: the challenges of cross-sector collaboration in Norwegian municipalities. Fire Saf J 92:1-8. https://doi.org/10.1016/j.firesaf.2017.05.001

Hammersley M, Atkinson P (2007) Ethnography: principles in practice, 3rd edn. Routledge, London; New York

Harper D (2004) Photography as social science data. In: Flick U, von Kardorff E, Steinke I (eds) A companion to qualitative research. Sage Publications, London; Thousand Oaks, $\mathrm{p}$ 231-236

Högström E (2018) 'It used to be here but moved somewhere else': post-asylum spatialisations-a new urban frontier? Social Cult Geogr 19(3):314-335 https://doi.org/10.1080/14649365.2016.1239753

KMD (2009) The tenancy act. Ministry of local government and modernisation, Oslo. https://www.regjeringen.no/en/dokumenter/the-tenancy-act/id270390/. Accessed 10 Apr 2017

Knorr Cetina K (2005) The rise of a culture of life. EMBO Rep 6(Suppl 1):S76-S80. https://doi.org/10.1038/sj.embor.7400437

Larsen IB, Topor A (2017) A place for the heart: a journey in the post-asylum landscape. Metaphors and materiality. Health Place 45:145-151. https://doi. org/10.1016/j.healthplace.2017.03.015

Latour B (1992) Where are the missing masses? The sociology of a few mundane artifacts. In: Bijker WE, Law J (eds) Shaping technology/building society: studies in sociotechnical change. Inside technology. MIT Press, Cambridge, p 225-258

Latour B (1993) We have never been modern. Harvard University Press, Cambridge

Latour B (1994) On technical mediation. Common Knowl 3(2):29-64

Latour B (2003) Is re-modernization occurring-and if so, how to prove it?: A commentary on Ulrich Beck. Theory Cult Soc 20(2):35-48. https://doi.org/ $10.1177 / 0263276403020002002$

Law J (2002) Objects and spaces. Theory Cult Soc 19(5-6):91-105. https://doi.org/ $10.1177 / 026327602761899165$

Lincoln YS, Guba EG (1985) Naturalistic inquiry. Sage, Beverly Hills

Lüders C (2004) Field observation and ethnography. In: Flick U, von Kardorff E, Steinke I (eds) A Companion to qualitative research. Sage Publications, London; Thousand Oaks, p 222-230

Lupton D (1999) Introduction: risk and sociocultural theory. In: Lupton D (ed) Risk and sociocultural theory: new directions and perspectives. Cambridge University Press, Cambridge; New York, p 1-11

Marcus GE (1995) Ethnography in/of the world system: the emergence of multisited ethnography. Annu Rev Anthropol 24:95-117

Mathar T (2008) Review essay: making a mess with situational analysis? Forum Qualitative Sozialforschung/Forum: Qualitative Social Research 9(2) Accessed 24 Oct 2017

McPherson P, Krotofil J, Killaspy H (2018) What works? Toward a new classification system for mental health supported accommodation services: the Simple Taxonomy for Supported Accommodation (STAX-SA). Int J Environ Res Public Health 15(2):190. https://doi.org/10.3390/ijerph15020190

Mol A, Law J (2002) Complexities: an introduction. In: Law J, Mol A (eds) Complexities: social studies of knowledge practices. science and cultural theory. Duke University Press, Durham, p 1-22

Moon G (2000) Risk and protection: the discourse of confinement in contemporary mental health policy. Health Place 6(3):239-250. https://doi.org/10.1016/ S1353-8292(00)00026-5

Murphy E, Dingwall R (2001) The ethics of ethnography. In: handbook of ethnography. SAGE Publications Ltd, Thousand Oaks. pp. 339-351

Nadai E, Maeder C (2005) Fuzzy fields. Multi-sited ethnography in sociological research. Forum Qualitative Sozialforschung/Forum: Qualitative Social Research 6(3). http://www.qualitative-research.net/index.php/fqs/article/view/22. Accessed 13 June 2017

Nelson G (2010) Housing for people with serious mental illness: approaches, evidence, and transformative change. J Soc Social Welfare 37(4):123-146

Parr H (2008) Mental health and social space: towards inclusionary geographies? Blackwell Publications, RGS-IBG Book Series, Malden

Phelan M, Fisher N (1993) Fire risk: assessment and management in long-term psychiatric patients. Psychiatr Bull 17(2):86-88. https://doi.org/10.1192/pb.17.2.86

Priebe S, Badesconyi A, Fioritti A et al. (2005) Reinstitutionalisation in mental health care: comparison of data on service provision from six European countries. BMJ 330(7483):123-126

Prus RC (1996) Symbolic interaction and ethnographic research: intersubjectivity and the study of human lived experience. State University of New York Press, Albany 
Rabinow P, Rose N (2006) Biopower today. BioSocieties 1(2):195-217. https://doi. org/10.1017/S1745855206040014

Ridgway P, Zipple AM (1990) The paradigm shift in residential services: from the linear continuum to supported housing approaches. Psychosoc Rehabil J 13 (4):11-31. https://doi.org/10.1037/h0099479

Rog DJ (2004) The evidence on supported housing. Psychiatr Rehabil J 27 (4):334-344. https://doi.org/10.2975/27.2004.334.344

Schulz J, Clarke J, Feeney M (2008) Case study-Special design of smoke detection system in a mental health facility in New Zealand. Fire Safety Sci 2008:1077-1087. https://doi.org/10.3801/IAFSS.FSS.9-1077

Spradley JP (1979) The ethnographic interview. Holt, Rinehart and Winston, New York

Steinke I (2004) Quality criteria in qualitative research. In: Flick U, Kardorff Evon, Steinke I (eds) A companion to qualitative research. Sage Publications, London; Thousand Oaks, California, p 184-190

Tabol C, Drebing C, Rosenheck R (2010) Studies of "supported" and "supportive" housing: a comprehensive review of model descriptions and measurement. Eval Program Plan 33(4):446-456. https://doi.org/10.1016/j.evalprogplan.2009.12.002

Xiong L, Bruck D, Ball M (2017) Unintentional residential fires caused by smokingrelated materials: who is at risk? Fire Saf J 90:148-155. https://doi.org/ 10.1016/j.firesaf.2017.04.020

\section{Acknowledgements}

The project was approved by the Norwegian Center for Research Data (nr. 50067). All participants provided written informed consent to participate before inclusion, and

anonymity was guaranteed to all participants.

\section{Additional information}

Competing interests: The authors declare no competing interests.

Reprints and permission information is available online at http://www.nature.com/ reprints

Publisher's note: Springer Nature remains neutral with regard to jurisdictional claims in published maps and institutional affiliations.

\section{(c) (i)}

Open Access This article is licensed under a Creative Commons Attribution 4.0 International License, which permits use, sharing, adaptation, distribution and reproduction in any medium or format, as long as you give appropriate credit to the original author(s) and the source, provide a link to the Creative Commons license, and indicate if changes were made. The images or other third party material in this article are included in the article's Creative Commons license, unless indicated otherwise in a credit line to the material. If material is not included in the article's Creative Commons license and your intended use is not permitted by statutory regulation or exceeds the permitted use, you will need to obtain permission directly from the copyright holder. To view a copy of this license, visit http://creativecommons.org/ licenses/by/4.0/.

(C) The Author(s) 2019 